\title{
Impressions and Transformations: A Psychoanalytic Study of the Effects of Early Linguistic Disruptions, Emotional Trauma, and of Testimony through the Study of Oscar Hijuelos' Thoughts without Cigarettes
}

\author{
Fernanda Carrá-Salsberg, $\mathrm{PhD}^{1}$ \\ York University
}

\begin{abstract}
This article takes a psychoanalytic approach to the analysis of Oscar Hijuelos' Thoughts without Cigarettes. Hijuelos' memoir is studied for the manner in which offers illustrations of the developmental significance of language and of the psycho-emotional and social effects that stem from its abrupt cessation. My work examines the significance of memory, as well as the transformative effects of writing: It is a look into the way in which this late writer's narrative conceals the paradox that embraced the affective relation he held with his first and later objects of affection, as well as with his first and second tongue. This paper studies how life-long narratives are of much significance to academics and professionals interested in the area of language and psychoanalysis. Through the analysis of Oscar Hijuelos' memoir I highlight the manner in which written testimonials often unveil writers' known and unknown histories of object-relations, introjections, projections, transferences, repetitions and need for reparation. Equally important, this article considers the manner in which Hijuelos' testimonials became the medium through which he articulated the perceptions of his experiences, and how such articulation created a space for him to eventually understand, transform and even attempt to heal from the dislocations and internal void that shaped and reshaped his hidden drives, life long needs and translingual subjectivity.
\end{abstract}

\section{Introduction}

In Thought without Cigarettes Oscar Hijuelos narrates his life-experiences between his Spanish and English languages. In a memoir published only two years prior to his sudden death, Hijuelos provides an interesting testimony of linguistic imbalance, emotional trauma, loss, linguistic replacements, identity shifts and search for love. Through stories of early experiences between Cuba and the United States, this American-born writer, of first generation Cuban migrants, lays the methodical grounds for what perceptually stood at the root of his libidinal attachments, his sense of self, and his personal and professional life within internalized tongues and cultures.

${ }^{1}$ Correspondence concerning this article should be addressed to Dr. Fernanda Carrá-Salsberg, Department of Languages, Literatures and Linguistics, York University, Toronto/Canada. E-mail: fcarra@yorku.ca 
Hijuelos begins his memoir by sharing aspects of his parents' pre-and post-marital lives, their socio-educational differences ${ }^{2}$, and the reason for their geographic re-location from Holguín, Cuba in the 1940s. ${ }^{3}$ He also introduces how, Spanish, the language he inherited from his parents, and spoke with his older brother and extended family, was the symbolic code of meanings that engulfed his earliest memories as an emerging subject: “...that language, Spanish, must have permeated me like honey, or wrapped around my soul like a blanked or, if you like, like a matilla, or, as my mother, of a poetic bend would say, like the sunlight of a Cuban spring" (p. 7).

Following the landscape of his childhood construction, this translingual writer turns his readers' attention to an incident that, borrowing from Freud (1893), amounted to the meaning of his obsessive act (p. 139). ${ }^{4}$ Hijuelos explains that at the age of four, while visiting his family in Cuba with his mother and older brother, he contracted nephritis, a virus that in those days inflicted a serious, life-threatening risk in children (p. 45). Upon their eventual return to New York, and following doctors' advice, Hijuelos was separated from his loved ones and isolated in English-speaking hospitals for a one-year period of time (p. 46). In his attempt to reconstruct his experience, Hijuelos writes:

The few things I do remember about my initial hospitalization -tubes shoved up me and medical smells, and dreary wards, and a terrible loneliness, blood being constantly taken and bitter-tasting pills - seem to have unfolded in the kind of darkness that children experience in bad dreams. Bloated and seeping blood, I must have felt that something had gone wrong, but did I even know? Was I even awake at first?... and even if I had been aware of it, what on earth could I have been feeling? (p. 45)

After explaining the conscious limitations of his memory, and how such poorly recalled experience formed part of a "dark hole" (p. 47), Hijuelos highlights the emotional and linguistic rupture that resulted from his trauma. As recalled by this author, in a brief sixmonth-span, he replaced his mother tongue with that of the English language. The most

\footnotetext{
${ }^{2}$ Hijuelos explains that his father came from a long lineage of Cuban farmers and his mother was the daughter of Spaniard migrants who belonged to Cuba's uppermiddle class (p. 14).

${ }^{3}$ His parents' migration to New York was unrelated to politics. Both parents left Cuba, their country of birth, in search for financial stability.

4 In "Beyond the Pleasure Principle" Freud (2006) explains that victims of distressing events demonstrate a fixation to the moment of the traumatic occurrence. Many become unable to release themselves from the moment of trauma and thus feel stuck in a state of alienation -with a non-integrated past and inability to envision a future-. Often these subjects relive their traumatic situation in their dreams and have the need to repeatedly describe their traumatic obsession in hopes of understanding and/or releasing themselves from their trauma (139).

Language and Psychoanalysis, 2015, 4 (1), 31-49 
striking aspect of his linguistic occurrence is that the sudden acquisition of English was concurrent with the immediate attrition of his primary language:

The partition between my mother and me became the story of our lives, I had absorbed

English from the nurses, doctors, and children of my acquaintance with some kind of desperate ease. English in, Spanish out, or at least deeply submerged inside me - from my childhood onward, I have long complicated dreams in which only Spanish is spoken (p. 8).

Knowing that generally "everything that takes place in the life of the psyche survives" (Freud, 2002, pp. 7-8), we may suppose that Spanish, the language that enabled his ego development and became intimately linked with his affective prototype, was the one lived symbolic code that remained etched within his unconscious, regardless of his conscious memory. At the conscious level, nonetheless, Hijuelos reasons that the act of becoming emotionally and linguistically distanced from this primary tongue stemmed from becoming ill in Cuba:

For a long time all I would know was that I had gotten sick in Cuba, from Cuban microbios, that the illness had blossomed in the land of my forebears, the country where I had once been loved and whose language fell as music to my ears... what I would hear for years afterward from my mother was that something Cuban had nearly killed me and, in the process of my healing, would turn my own "Cubanness" into air (p. 45).

When exposed to a traumatic experience, trying to find a reason and a projected blame for a presumably unfair experience is a natural occurrence. As an adult, Hijuelos described having attributed his sickness, physical weakness and life-long restrictions to his early trip and by extension, to its hosting country, language and culture. However, knowing that "all forms of mentation occur in concurrence to one another" (Akhtar, 2009, p. 220), we cannot overlook the unconscious underpinnings of his linguistic attrition and cultural distancing. In fact, what becomes most meaningful to this article's discussion is that Hijuelos' incident offers a glimpse into what occurs when a basic human need and essence are interrupted at a young age. As recounted by this writer, the response to his linguistic and emotional rupture was not only manifested through the celerity in which he replaced Spanish with the English language, but also in the manner in which the loss in socio-emotive function of his primary tongue coincided with the act of emotionally drifting apart from his mother: 
Of course, she was my mother, I knew that - she kept telling me so - "iSoy tu mamá!"

But she also seemed a stranger, and all the more so whenever she started to speak

Spanish, a language which, as time went by, sounded familiar and oddly strange to

me...I remember nodding at her words; I remember understanding my mother when

she said... ¿Sabes que eres mi hijo? (“Do you know you are my son?”) (p. 6)

There is much we can extract from this quote. Some may suggest that little Oscar responded to his loneliness and desire to belong by embracing his host environment, and disowning his parents and the chief mark of their foreignness: their Spanish language. ${ }^{5}$ Yet, as a Kleinian, I would like to acknowledge that the feelings we have towards our first object(s) of affection become unknowingly and most inevitably transferred onto the language she or he speaks, onto the system of meanings that links us verbally and emotionally to our primary caregivers. Thus, it makes sense to assume that as a four-yearold child immersed within a foreign language and an unfamiliar environment, little Oscar could not have understood the reason for his mother's absence. Having been perceptually abandoned made him feel lost, afraid and confused. It is also natural to suggest that he most likely felt angry towards his mother for leaving him behind while he needed her the most. Grounded in these circumstances, I propose that the confounding emotions Hijuelos experienced towards his mother were transferred onto the feelings and sense of worth he experienced towards her Spanish language. Thus following his trauma, Spanish -the symbolic system of meanings integrated within his affective prototype- became part of a lacerated and demoted essence that could no longer connect him to the social and support his subjective development.

\section{Our Primary Language and Winnicott's Transitional Phenomenon}

To grasp Hijuelos' response to his early trauma, let us also consider the idea of language as part of Winnicott's (2005) transitional phenomenon. In Playing and Reality, Winnicott offers the definition of a transitional object as one that helps infants transition from dependence to independence and thus, individualize as subjects. He stresses that such object can only become developmentally relevant to the child when the internal object the magically introjected breast- is alive, real and not persecutory (pp. $13 \& 19$ ), after the 'good enough mother' provided her child with enough opportunity for illusion and, later, gradual disillusionment (pp. 15-17). This child psychoanalyst explains that if the external object's, primary caregiver's, efforts do not meet the needs of the infant, then the internal object fails to have meaning, a situation that results in the meaninglessness of the transitional object as well (p. 13).

Winnicott's theory discloses the difficulty perceived by subjects who experienced a sense of emotional discontinuity during their foundational stages of development. It speaks of the challenges undergone by those who have been raised by primary caregivers who, for a

${ }^{5}$ This valuable comment was offered by a blind reviewer for this article.

Language and Psychoanalysis, 2015, 4 (1), 31-49

http://dx.doi.org/10.7565/landp.2015.002 
number of possible reasons, were incapable of providing a good enough environment that nourished their child's or children's healthy developmental growth. Winnicott exposes the possible consequences of such deviance by providing two key examples: one of a male, and another of a female patient. Winnicott explains that as a child, the male patient was difficult to wean. He was fully dependent of his mother's presence and affection, and was incapable of becoming attached to any tangible article. Winnicott describes that as an adult this subject had no significant emotional relation with anyone other than his mother, and consequent to this isolating attachment, this man moved apart from his mother, finding employment away from his hometown (pp. 9-10).

Winnicott supports his theory by also offering, in more detail, the case of a woman who as a child was separated from her mother for extensive periods of time. With the use of vignettes we learn that what affected this patient throughout her young and adult life was the feeling of internal disconnection that developed from her mother's absence. Winnicott explains that she was haunted in her dreams and felt a sense of emotional dislocation in her day-to-day perceptions. Eventually, this patient felt that the only thing real was the consistency of her nostalgia, the ongoing sense of absence, or amnesia (pp. 30-32).

Both of Winnicott's case studies support a theory grounded in the long-term implications of either not being efficiently weaned, and/or not having the occasions for illusionment. For children, not having the opportunity for illusionment and disillusionment renders their first possession developmentally meaningless, and thus unfit for their transition towards becoming healthy subjects. Under these circumstances subjects eventually feel that their personality is not well integrated: they sense that "something is wrong" and tend to be unhappy with themselves. Such developmental deviation, continues Winnicott, inevitably trickles onto the subjects' self-other relations (pp. 89-90) and correspondingly, into their interactions within their third space. ${ }^{6}$

Even though Winnicott's developmental theory is grounded on infantile events, and although his transitional 'object' is understood as a tangible article ${ }^{7}$, his theory is nevertheless applicable to Hijuelos' childhood occurrence within language. Beginning with this writer's age, one can argue that since he was hospitalized as a monolingual Spanish-speaking subject, becoming plunged into a foreign language and reality situated

${ }^{6}$ Britzman (2006) offers a definition of the third space as an area in which self-other interactions become governed by an unconsciously shared "give and take". It is a terrain through which we unknowingly respond to others' psychic histories and resulting affect as much as others respond to our own history of affect (pp. 42-44 \& 49). Britzman's definition is of significant value to our understanding of language: Since our symbolic code of meanings becomes an interactive, propelling and encoding register, we cannot disregard our tongue's inevitable implication within this space, especially after accounting for the way in which language holds together our known and unknown histories, perceptions and experiences that mark our responses towards and interpretations of others, and of ourselves in relation to others.

${ }^{7}$ A transitional object is described by Winnicott (2005) as an objectively perceived article chosen by the child, such as a blanket or a teddy bear, that is meant to offer the child the comfort and safety that is needed for her transition into becoming an individual (p. 130). 
him at an infantile stage of language. ${ }^{8}$ Taking into account the unconscious law of relationality, moreover, we can conceptualize how such an occurrence made this fouryear-old relive a primary developmental stage, and therefore feel the unconscious need to recreate his infantile cultural experience.

While remaining with Winnicott's descriptions, even though language is indeed an objectiveless phenomenon, by definition it nevertheless intersects with Winnicott's conceptualization of a transitional object. If we look into psychoanalytic theories that define the affective meaning a primary tongue, we see that our first symbolic system of meanings is described as one that is intimately linked to our earliest and later developments, and "to our affective prototype" (Britzman, 2010). Our mother tongue is, quoting from Akhtar (1995), "the link to the earliest maternal imago" (p. 1069) and paradoxically, the essence that enables a child's transition as a subject. Adding to such descriptions, our primary tongue is a subjectively perceived developmental trait that, in agreement with Phillips (1998), enables the child to move away from her first love(s) and eventually become a subject within the larger community of competent speakers (pp. 4345).

After drawing attention to such claims, I propose that if our language is a phenomenon that forms part of subjects' cultural area of experiencing, then for Hijuelos, as it was for Winnicott's patients, having had his external object absent and non-nurturing during his time of need, made his internal object lose its developmental relevance. As a result, the transitional object, his Spanish language, became socially and intrinsically unfitting or, borrowing from Winnicott, developmentally -and socially- meaningless.

\section{Identifying Dislocations in the Developmental (Dis)Continuum of an Early Migrants' Language Learning and Subjectivity}

Hijuelos' memoir allows us to further conceptualize the manner in which early historical traumas infringe upon subjects' lifelong realities, and upon their self-other relations. In Thoughts without Cigarettes we note how the ramifications of this writer's childhood experience created a sensed dislocation within his personality, which in turn affected the manner in which Hijuelos believed to be perceived by his parents, and by those who formed part of his third space:

...when it came to something as important as restoring that which was taken from me,

a sense of just who I was, I doubt that, as with my mother, it occurred to him [his father] that something inside of me was missing, an element of personality in need of repair (p. 67).

\footnotetext{
${ }^{8}$ This assumption is founded on one of Erwin Stengel's (1939) arguments. In "On Learning a New Language" this former adult migrant and psychoanalyst, argues that when subjects, regardless of age, are immersed within a foreign language and reality they become re-submitted to an "infantile stage of language learning" (Stengel,
} 1939, pp. 471-473). 
This quote offers a description of how, similar to Winnicott's patient, Hijuelos was dissatisfied with himself and with his socio-emotional reality. In retrospect, he sensed that the gap or dislocation created by his emotional and language-related trauma rendered his persona "in need of restoration". His recollections highlight the manner in which language not only shapes subjects' socio-emotional and cognitive developments, it also influences the ego's libidinal attachments. Beginning with the relationship he held with his mother, we could assume that Hijuelos' resistance to her may also be tied to her eloquence when relating in Spanish, a language that became second to the writer. In the first chapter of his memoir, Hijuelos describes his mother as "a high strung individual" (p. 3), who had enjoyed, as a child, an aristocratic upbringing as part of Cuba's uppermiddle class (p. 13). He presents Magdalena as a well-spoken person who was known for "winning prizes for writing essays, and poetry" at school (p. 14). Years following his father's death, Hijuelos explains how his "artistically inclined" mother turned her attention back to Spanish poetry, a talent Hijuelos describes as "sophisticated" (p. 330).

As a researcher in migration and language, I must add that this mother-child detachment was also created by their linguistic condition as first and 1.5 generation migrants. The gap Hijuelos described experiencing with his mother was not only linked to his childhood experience, but also to his inability to relate with his mother at her linguistic level -when speaking Spanish-, and to his mother's inability to fluently interact with her son in English, his dominant tongue. Adding to their linguistic challenge(s), their void was evidently and inevitably intensified with his schooling, through young Hijuelos' internalization of the host language and culture. As a subject who has experienced migration and the sense of being in-between languages from an early age, I understand that the way we sound, and not just what we say, influences the manner in which we are perceived by those who surround us, and thus on how such perception influences the way in which we understand our own projected selves in relation to others. This is an aspect of our speech that is clearly stated in Hijuelos' text when he recounts his feelings, once again, towards his mother and her 'broken' English (p. 74).

Another interesting aspect of this writer's language-related memoir, one that brings me back to my own experiences as a translingual subject, is that the author's early perception of his parents' speech affected, by way of relation, his own self-perception:

I lived in dread of being called on, and lacking self-confidence, I always felt that I had to play catch-up when it came to reading and writing, over which I agonized, all the while thinking that I was not very smart. And not just because I was often too distracted by my own anxieties to concentrate well, but out of some sense that my mother and father's limitations, when it came to English, had become my own: Just attempting to read - anything really - I'd feel as if I had to swim a long distance through murky water to fathom the meaning, and, at the same time, though I eventually improved, shell-shocked though I was, I always had the sense that the 
language was verboten to me... No matter how hard I tried, or how well I did on the

tests, I secretly believed that my mind was essentially second-rate- all the other kids

just seemed brighter than me (p. 75).

What makes this passage thought provoking is that it serves as an example of how for Hijuelos, his parents' peripheral or marginal linguistic membership assumed a social weight on him as a child, on his feelings, his self and self-other perceptions and his imagined aptness within the host language. Since our primary identification as children tends to be intimately connected to our parents or primary caregivers, at least until we develop our own set of conscious histories and experiences as separate subjects, we may reflect their image onto ourselves. For Hijuelos, perceiving his parents' apparent ineptness with the dominant tongue and within the host community, made him internalize, as a child, such view onto himself.

Understanding that language aids in encoding, processing, retrieving and expressing information, we can deduce that during his childhood, Hijuelos' sense of difference also rested in his limited exposure to the English language. Following his hospitalization, Hijuelos describes being homeschooled for a year by his non-English speaking mother ( $\mathrm{p}$. 73). Concurrent with his homeschooling, his poor health restricted his outdoor playtime with English speaking children. This is observable when he explains: "I felt, from the start with my mother by my side, tremendously self-conscious and uncomfortable, not just because I've been apart from other children for so long, but because of the way I'd come to believe that something is wrong with me" (p. 74). Hijuelos tells his readers that when he was finally registered in grade one, he felt othered. Not having the linguistic tools that enabled critical learning, moreover, made him feel academically challenged during his primary years.

In addition, by considering the concept of language, culture and identification, we should also turn our attention to the unavoidable authority that stems from a dominant culture. In Hijuelos' case, we see how such authority infringed upon his subjectivity: “...in New York...there were always people to stare resentfully if they overheard someone speaking Spanish on the street..." (p. 26). Once at school, he began to see the world and his existence through the lens of the host culture. This introjection is evident in the ways in which he disapproved of his mother's linguistic struggles, and even in the manner in which he attempted to break away from his heritage culture:

My idols...were those icons of the British Invasion, from the Beatles to the Rolling Stones... Since I really had little identity of my own - except as this "son of cubanos" who had once been sick and didn't identify with Latin culture in general, for when I heard Spanish songs, they always sounded passé and locked in some perpetual, unchanging past, and I didn't even consider my Spanish anything I should try to 
improve upon - I spent those (teenage) years trying to become anything else but what I should have been, Oscar Hijuelos (p. 155).

As a 1.5-generation migrant he viewed the host culture as a desired goal, even if it was not always felt as an all-embracing culture. The narrator's desire to reject his heritage is provided when he expressed his longing to have a different name:

I recall feeling envious over a cowboy's name Rawhide...Years later, when I first thought I might publish somewhere, I seriously considered adopting the nom du plum Oliver Wells, and to jump even farther ahead, during the kind of journey I could never have imagined as a child, I signed my name on the guest registry of the archeological museum Ankara, Turkey, as Alexander Nevsky, the kind of thing I'd do from time to time (pp. 76-77).

Hijuelos' ethnic name "grounded his social existence" (Bohórquez, 2008, p. 49). It rooted an existence that he, as a young subject, openly rejected. While providing us with instances of life reality ${ }^{9}$, we note how this writer internalized dominant attitudes, and projected them in the form of embarrassment towards his parents, his roots and the Spanish tongue. Equally important, this writer's dissociation within Spanish is not only evident in his playful choice of names and/or in his outspoken attitude toward his parents' speech and migrant status. By looking at this self-narrative's text reality ${ }^{10}$, we note that his linguistic relation to Spanish becomes clear through his grammatical mistakes. Whether Hijuelos' grammar reflect his life-long personal troubles, or depict a combination of linguistic attrition and cessation in language learning, it is common sense to note that his poor use of Spanish grammar hints to the subjective relation he holds with his mother tongue. Considering that as an adult Spanish was a language he understood, but barely spoke, and knowing that Hijuelos was in a position to find Spanish-speaking editors for his memoir, and yet refused to do so, leads to the assumption that his 'personal' use of language expresses a developmental detachment with his primary tongue, and a conforming attachment to English, the language he claimed as his own.

\footnotetext{
${ }^{9}$ In "Autobiographical Narratives as Data in Applied Linguistics", Aneta Pavlenko marks the distinction between three interconnected types of information gathered from autobiographical narratives: text, subject and life reality. "Text reality" refers to the way in which writers narrate their stories -how they use language; "subject reality", refers to how events were perceived by the writer; and "life reality" is a study of how things are or were; it is a look into the overall attitudes and behaviours that influence-or influenced- the subject (Pavlenko, 2007, p. 166).
} 


\section{Interpreting the Unconscious through the Act of Writing}

As once mentioned by my former thesis supervisor Deborah Britzman (2010), an interesting aspect of language is that it "describes while embodying a process" (pp. 4063 , one that accounts for the juxtaposition of the inner self with the social. Through the study and application of theory, we learn that language is embedded in desire, and such desire accounts for our actions, attitudes and behaviours that together shape and reshape us within our complexity as split subjects. The significance of Hijuelos' self-narrative also rests in how it exposes the influence language has had on this late transligual writer. Hijuelos' memoir provides descriptions of language as a process, as one that embeds itself in the subject's affective history, while exposing unconscious mechanisms that slip through the use of his words.

Beginning with transference, with a careful reading of Hijuelos' words and while focusing on this writer's relationship with his parents, we can deduce that he has transferred the affection he felt towards his first love-object his loving, yet perceptually absent mother to his father, who, regardless of narrated idealizations, is repeatedly described as an absent figure:

I can only recall his kindness...I got so attached to him that I came to re-write my history in the hospital...Fabricating his presence in memor...I just found something comforting about him, even if I would never get to know what he was really about (p. 66-67).

Instances of his father's absence are written throughout the beginning and middle of his text. Following the most recent quotes, this writer continues to draw attention to Pascual's absence by stating that he "never taught me anything at all" (p. 67). Later, knowing that the author's illness inflicted a lifetime of physical examinations, he mentions that unlike his mother, his father "never once accompanied me to the doctor's..." (p. 77). Pascual's distance was inevitably heightened, by way of response, when the writer was a teenager. This becomes evident when Hijuelos recounts their last exchange:

A month or so short of my eighteenth birthday, I was so self-involved that on the day I

left for Miami, and my father, sitting on our stoop, wanted to embrace me just before I got a lift down to Penn Station in a neighbor's car, I sort of flinched and waved him off...feeling slightly put-upon seeing him smiling -perhaps sadly- at me as he settled on that stoop again and reached for a cigarette. I can recall wondering if I'd been a 
little cold... Of course now I wish I'd been more receptive to him in those moments, but the truth is, I didn't know it would be the last time I'd see him alive...(p. 167)

As described by this writer, his father's identity was linked to being Spanish and Latin: "he possessed an abundance of down-home Cuban warmth" (p. 66). Prior to his father's death, Spanish reflected an inner subjective element and a language with which the author could not connect or process: "...I simply tuned out... when it came to Spanish, some busy emotions in my head preventing, as it were, my momentary concentration" ( $p$. 151). As explained by Hijuelos, Spanish was part of a language and culture that while he was a child, a teenager and later, a young adult, was not perceived as his own:

One of those what-on-earth-are-you-doing-with-your-life evenings. I was in the kind of mood where just to hear español spoken on the street irritated me...(So maybe I was a white motherfucker after all)...(p. 293)

In his memoir Hijuelos makes repeated reference to his light skin and thus, to his distinction from -what he describes as- the stereotypical Hispanic looks. Time and again he describes feeling disconnected with the language and culture that made him feel as an outsider. Yet there is perhaps more to this quote than what readers may perceive in passing. With Hijuelos, understanding the Oedipus relation, and the anger and disconnect he felt as a child towards his mother, brings me to highlight the extent of which his words, specifically with his use of the term 'motherfucker', depict the mixed feelings he experienced towards his mother and, by extension, toward her language and culture. Here we see that this bracketed sentence offers yet another instance of how our feelings towards and comfort within a language and its corresponding culture relate to the disclosed and hidden emotions we feel towards those who speak and therefore represent it.

Hijuelos' self-narrative presents behaviours that seem shaped and defined by his life's vicissitudes. An event of much interest to my study relates to the writer's attitudinal change towards the Spanish language and culture following his father's death. As Hijuelos layers his present emotions and assumptions into the memory of his past, we notice that Pascual's irreversible absence becomes a pivoting point in Hijuelos' career, awakening his desire to learn about his migrant culture. Such change can be linked to both Felman's and Winnicott's theories. Beginning with Felman (1987), the relationship between the father, language and the law takes us to Lacan's discussion of the symbolic within the Oedipus Structure. Felman states that for Lacan, the individual is initiated through the father's first 'no', and that such articulation aids in the development of the infant's ego boundaries. Based on this Lacanian assumption, Hijuelos' Spanish language was not only linked to his mother, and an early childhood image of her absence, but also to his father's ongoing absence and disconnect.

To better understand Hijuelos' unconscious relation to his father, let us once again draw a parallel between this writer's reality and that of Winnicott's female patient. Returning to 
Winnicott's theory (2005), we note that as experienced by his nameless female patient, Hijuelos' recalled events outline a paradox. Half way through the memoir we read that Hijuelos only began to feel his father's presence following his passing: "I felt my father's presence all around me...I felt his absence... anything I wrote eventually, however veiled, in some mystical way led back to my pop...I was haunted by his memory..." (p. 264).

At this pivoting point in his life, Hijuelos also reconnects with his Latin roots. He begins to appreciate his Cuban identity, starts to listen to Spanish music and becomes eager to read Latin American literature. Quoting from Hijuelos: "I read everything I could get my hands on, without any overriding design, a kind of madness - or book lust - coming over me...I dove more deeply into the sea of Latin American letters and found those waters increasingly warm" (p. 219).

Concurrently, under the guidance of his professor Bathelme, Hijuelos experienced transference through his writing: "I began wanting to write more and more about Cuba. It simply possessed me. Reawakened memories..." (p. 219). Relevant to our discussion, during this time Hijuelos writes his first immigrant novel, The Mambo Kings, which outlined his father's lifelong experiences:

...my novel, The Mambo Kings, was my way of...holding a conversation with him, though he had long since been dead. His spirit, for better or for worse, in its kindness and gentleness, in its melancholy and, alternately, exuberance, his love for life, fear of death, his passions and vices - down to the thousand drinks he had consumed and cigarettes he smoked were all transformed, in that book. Or to put it differently, he was alive again, if only as a momentary illusion...(p. 367)

In addition to his novel, his father's passing eventually awakened his desire to understand his experiences through the act of memoir writing. ${ }^{11}$ Aside from the dynamics that influenced his attachment with his deceased father, when Hijuelos describes both of his parents there is evidence of idealizations and possibly of splitting. However, before pointing at such mechanisms and looking into the manner in which these shaped this writer's discourse, I would like to draw our attention to Melanie Klein's theory, once again, for an even deeper understanding of Hijuelos' text.

In "The Origins of Transference" Melanie Klein (1975) explains that an infant's existence is governed by anxieties, phantasies and defenses that initiate and influence primary and later object-relations (pp. 48-54). From the onset of postnatal life, anxieties and a split between hate and love, hunger and gratitude governs infants' feelings (p. 49).

${ }^{11}$ In his self-narrative he highlights his father's smoking throughout the text. Although the writer also describes himself as a smoker, through such references we can deduce that in his memoir's title: Thoughts without Cigarettes, 'cigarettes' are a metonym representing his father. 
During the first three to four months of life the child experiences persecutory anxieties. He or she develops a relation with aspects of his or her mother's breast. The breast is perceived as good when it satiates the infants' hunger and is perceived to be bad when the child feels hungry.

Klein (1964) also explains that while hungry and the child's anger and hate erupt, he or she projects onto the bad breast feelings that, in phantasy, are destructive. Such negative feelings dissipate when the infant's primary needs are satiated through feeding. While being fed he or she takes in, or introjects, the good loving breast (pp. 58-59). However, after being nourished and feeling loved the infant is overcome by guilt and fears retaliation from the bad breast. Klein suggests that as a defense against that 'retaliative' bad breast, the infant turns the good object -breast- into an ideal one as a protection against what is perceived to be a dangerous and persecuting object. As Klein proposes, these processes of splitting and idealization, which stem from the very early stage of persecutory anxiety, influence ongoing object relations (p. 49).

With Hijuelos, this splitting between good and bad, desirable and undesirable is seen throughout his text. It is legible, specifically, in how he perceives his parents on the basis of their language. Through retrospective manoeuvres of memory, the author often recalls his father's charm, while highlighting his ability to speak English and learn other languages: "...well liked and affable, working around not only other Cubans like himself but immigrants from Italy, Greece, and Poland (whose languages he began to absorb)" (p. 26).

At times, however, this author expresses the opposing sentiment when describing his mother, who's English he openly criticized:

I can only recall his kindness [the author's father's], and with the bias I eventually developed toward my mother because of language, I got so attached to him that I came to re-write my history in the hospital...Fabricating his presence in memory...(p. 66)...He'd speak to me in English, not always, but when he did, it was with a quiet authority and without my mother's befuddlement and confusion...(p. 67)

Aside from transferences, idealizations and splitting, the writer's unconscious is brought to the surface through the description of a hallucination and of one of his most prominent dreams. Following the death of his father and after obsessing with his ghostly presence. Hijuelos narrates:

At night, I'd worry about falling asleep and seeing his ghost. I'd...awaken, my heart beating wildly, from an impression that my pop was just outside in the hall waiting for me, as if he wanted to take me with him. One night I walked into the darkness of the 
living room, where I saw my father, or the shadow of him: he spoke to me, in Spanish, of course, saying: Soy ciego - "I'm blind". And then he said: "Por favor, abra la luz" Please turn on the light. When I did, he told me "Thank you" and simultaneously vanished. I swear this happened, dream or not, that's what I heard...(p. 265)

Since hallucinations, according to Winnicott (2005), are dream material (p. 31), I will treat this scene as a dream by applying Freudian theory to a possible interpretation: The author's acknowledgement that his father never took much time to connect with, and pay much attention to him, brings me to link the father's blindness to the son's conscious and unconscious interpretation of his father's unawareness of, or blindness. In addition, in Hijuelos' narrative we can discern condensations stemming from traces of the ongoing guilt and obsessions that haunt him in his waking hours. The stress that erupted from him writing about his father and becoming emotionally consumed over his memory had expressed itself in his somatic reactions:

In my self-mortifying Catholicism, I eventually came down with the worst case of eczema...My arms, chest, back, and neck were raw and dry; high-strung and feeling guilty, I lived with a picazón - an itching - that drove me crazy and intensified every time I'd sit down to write (p. 266).

As described by Hijuelos, his bodily reaction to such stress, however, subsided after having a pleasant dream that involved his father and the act of forgiveness:

Walking in a meadow, maybe in a place like Cuba, in the distance I beheld a river, and in the river there stood a man. As I approached, I could see it was my pop, Pascual, awaiting me. There he told me, shaking his head: - "Por que te moritifiques?" "Why are you torturing yourself so?" And with the kindest of expressions on his face, he, reaching into that water...washed over my arms, my face, my back...I do remember feeling a sense of relief, and, though a dream it may have been, in the morning when I awakened, my skin had cleared of its soreness (p. 266).

It is common sense to state that this dream depicts the writer's desire for reparation. As mentioned, his distance from his father, specifically during the last awkward moments 
they spent together -when Hijuelos was leaving for Miami, and his father attempted to embrace him- combined with their ongoing emotional distance, retrospectively triggered pain and guilt. Thus in his dream we see the true meaning of wish-fulfillment ${ }^{12}$, especially since the author, by way of his dream, felt absolved and cleansed by both the water and his father's loving arms.

Another significant aspect that takes us into the unconscious relates to Hijuelos' repetition of the event of his trauma. When relating to others, the writer's emotional disconnection becomes palpable when he downplays the experiences and memory that led to his failed marriage: "...I finally did get married to my girlfriend of some three years, Carol, think it was 1975..." (p. 225). The details of their marriage are barely narrated. Pages after focusing on his unsuccessful attempts to find himself as a writer he resurrects his former wife, Carol, by disclosing the eventual end of their relationship.

Not having been tuned to her concerns, Hijuelos describes feeling shocked one evening when, after returning home from work, he found that his wife had emptied their apartment of her possessions. He then explains that her reason for leaving him, her logic, was written in a note she posted on the fridge. Aside from her apology, nevertheless, the content and emotional relevance of her letter are never shared, even minimally, with his readers (pp. 247-248). Another interesting aspect of the description of his failed marriage rests is that its significance does not seem to rest in its emotional worth. Instead, the event of his break-up appears to relate to the manner in which such occurrence incited Hijuelos to continue with his writing and eventually flourish as a novelist:

Oddly enough, suddenly freed up, after an increasingly fallow period of writing, and without much of anything better to do with myself, and after hearing for so long the opinion that the last thing in the world I could ever be was a writer, I started finding my feet in that regard again (p. 248).

Another indicator of his ongoing emotional disconnection is clear towards the end of his memoir when Hijuelos mentions, in passing, that he was emotionally involved with a female friend. It is essential to note that while reminiscing about his emotional affairs all acknowledged attachments are mentioned by name. This, however, is not the case when he acknowledges receiving an exciting call for the award of the Pulitzer Prize for his novel The Mambo Kings. At this point of his narrative, on the last four pages of his memoir, out of the clear blue he makes reference to, perhaps, his most recent girlfriend, who, in his entire text, remains nameless (p. 363). The significance of such oversight brings us once again back to Winnicott's theory and the case of his female patient. Grounded in Winnicott's thoughts, it is natural to suggest that this girlfriend's presence in Hijuelos' life would only become tangibly restored through the passing construction of a

${ }^{12}$ In "Beyond the Pleasure Principle" Freud (2006) explains that the nature of -nonaccident-induced-dreams- are to "conjure up pictures [imagined and unimagined events/memories] from the time when the patient was healthy, or else pictures of the return of health that is hoped for in the future" (p. 139).

Language and Psychoanalysis, 2015, 4 (1), 31-49

http://dx.doi.org/10.7565/landp.2015.002 
layered memory, by means of the possible absence incurred by a conceivable breakup. In other words, her presence, just as that of his father, would only feel as real and thus, noteworthy of genuine recognition, following her absence.

Now my interest in the study of language and psychoanalysis makes me feel inclined to draw a parallel between Hijuelos' response to his mother tongue with his response to his father ${ }^{13}$. As described by this author, growing apart from his primary language increased his attrition-rate and, over time, his ability to sound and feel Spanish. Yet regardless of such disconnection, during his adult years his Spanish became noteworthy of regard, becoming 'his' only after he experienced its sensed loss. Such occurrence supports one of my initial arguments founded on the manner in which subjects' relation to their first tongue interrelates with their foundational history of affect, which in Hijuelos' case is tied to a loss of love. This writer's response to the Spanish language supports my discussion of language as a transitional object, as one that, in his particular case, could only be sensed as real following its apparent absence.

For this late writer, his history became a list of repetitions initiated by the absence of his mother, and followed by that of his primary language, his father and later loves. As seen in this published memoir, except for his living mother, his loved ones were not openly acknowledged unless there was an interruption or cessation of their physical presence. In addition, this writer's unknown affective attachment to Spanish is exposed to readers when he describes being in Rome and falling in love with the Italian language:

...the bel canto of the Italian language itself, which for some reason I felt far more at ease navigating than even my ancestral espanol. In fact, I'd use the Spanish I more or less improved upon during my recent travels to help me get along with Italians (down in Naples, the Italian almost sounds like Castilian sometimes). They understood me completely, and, because I had no emotional turf to defend, I eventually flourished (p. $300)$.

Similar to Elias Canetti's feelings when taken back by the sounds of the Slavic tongue (cited by Heller-Roazen, 2005, pp. 174-175), for Hijuelos, Italian represented the 'echo' of his primary language. It became the language that awoke his affect by unknowingly bringing back the warmth and love he experienced as an infant. Since Italian was not directly linked to his childhood trauma, the author, without "having an emotional turf to defend" was allowed to become engulfed by its words and sounds, which together brought back emotions that could only stem from a romance language that resembled his very own.

13 I would like to highlight that my postulations are founded on this late writer's autobiographical narrative, and not on post-memoir experiences. 


\section{Conclusion}

For those of us who have experienced a linguistic disruption at an early age, in an attempt to conceptualize its inner meaning and its tie to our subjectivity, we often try to understand the depths of our perceptions, attitudes and behaviours within language(s) through the use of our, and often most prominently, lived symbolic code. Some of us turn to theories in search for meaning, while others write autobiographical testimonies in hopes of "giving their lives meaning across time" (Pavlenko, 2007, p. 164), symbolizing their experiences and integrating the internal and external "I" that will always exist within language (Derrida, 1996, pp. 28-29). Conceptualizing our inner need to grasp our occurrences is key to the understanding of Hijuelos' symbolic motive. It is also important, I suppose, to the meaning of my own choice of study, a choice that inevitably leads to the sharing of a not so recent memorable event, and a corresponding afterthought. This takes me back to my second year as a doctoral student, when my former professor and supervisor, Deborah Britzman, asked me why we obsess with our beginnings? Such question left me thinking and later reminded me of a statement taken from Friedrich Nietzsche (c1980)... that "the tree is always in love with its roots" (p. 20).

Of course there is much we can extract from this decontextualized metaphor. I will nevertheless take the liberty of linking it to this article and of focusing my discussion on the following consideration: Since love often leads to a range of obsessions, perhaps out of our need for love, we obsess with our beginnings, with the way our parents were and may still be, with the manner in which we relate and related to them, and with the conscious and unconscious feelings that resulted from the early and even later tensions that stemmed from their authority. This well-known obsession, which forms the base of psychoanalytic discourse, rests in our human need and innermost desire to understand our inner and social selves.

Hence, we often try to learn and to recognize the buried drives that form and impact our attitudes, inhibitions and our overall actions: the hidden forces that shape the enigmatic subjects we are today. We strive to understand our feelings and decisions, along with our behaviours and socio-emotional relationships, simply because these aspects of our lives define our existence and our place within our shared world, within a world that changes, while often remaining the same, within a shared and personal world that is mostly mediated, understood, misunderstood and always felt through and within the use of our inescapable language.

As I demonstrated with the analysis of Hijuelos' memoir, this endless search offers within its description a process that takes us directly and indirectly to our affective histories, to histories that, once again, develop from within, and are understood through, this paradoxical phenomenon we call language. In this paper I have established how the feelings one experiences towards our first object(s) become incorporated as part of the ego's affective prototype, and how such emotions become transferred onto subjects' preceding relationships. I discussed the importance of a mother tongue and of how, along with, or aside from our first object, this language becomes part of our affect, by posing as “a representation of a representation" (Winnicott, 2005, p. 54; Derrida, 1982, p. 312).

Hijuelos' response to his two languages is presented directly and indirectly in his text. By reading his memoir we learned that throughout his life this late writer was torn between the tug of his primary language, which represented the language of his parents and of his

Language and Psychoanalysis, 2015, 4 (1), 31-49

http://dx.doi.org/10.7565/landp.2015.002 
childhood trauma, and that of the English language, the tongue that became linked to introjections from the host culture. Yet, regardless of the conscious and social significance of his claimed English tongue, Spanish, the language he attributed to migrants, the tongue that became almost forgotten and socially downgraded during his many years in the United States, was still the language that engulfed his affective history. For this writer Spanish became the symbolic code of meanings that represented his infancy, and thus his early moments of nurturance, love and dependence. Equally important, Spanish was the language that preceded, while paradoxically becoming, a vibrant aspect of his writing, it became part of the 'meaning of his obsessive act', and his conforming need to put into words and therefore understand the dynamics that embraced the personal and shared reality that formed and informed his third space.

\section{Biographical Note}

Fernanda Carra-Salsberg has been a postsecondary foreign language educator for the past fifteen years. Born in Buenos Aires, Argentina, her interest in language, culture, migration and identity formations stems from her repeated migrations as a child and an adolescent, and from experiences as a language pedagogue. She has taught English as a Second language and Spanish. Carra-Salsberg is currently teaching advanced Spanish Grammar and Spanish for Native Speakers at York University, Canada.

Carra-Salsberg has obtained a BA (hns.) in Spanish Language, Literature and Linguistics at York University, a B.Ed. in Second Language Acquisition and History at OISE, University of Toronto, a MA in Spanish at the University of Toronto. She has recently completed her $\mathrm{PhD}$ in language acquisition, language philosophy and psychoanalysis at the Faculty of Education, York University. 


\section{References}

Akhtar, S. (1995). A third individuation: Immigration, identity, and the psychoanalytic process. Journal of American Psychoanalytic Association, 43, 1051-1084.

Akhtar, S. (2009). Comprehensive dictionary in psychoanalysis. London, UK: Karnac Books.

Bohórquez-Arcila, P. (2008). Living between languages: Linguistic exile and selftranslation. (Doctoral Dissertation). York University, Toronto.

Britzman, D. (2006). A note on "Identification with the Aggressor". In Novel Education: Psychoanalytic Studies of Learning and Not Learning (pp. 41-59). New York, NY: Peter Lang.

Britzman, D. (2010, September). Psychoanalytic Theory and Pedagogy. Graduate Seminar. York University, Toronto.

Derrida, J. (1982). "Signature, Event, Context". Margins of Philosophy. (A. Bass, Trans.). Chicago: University of Chicago Press.

Derrida, J. (1996). Monolingualism of the other and the prosthesis of origin. (P. Mensah, Trans.). Stanford, CA: Stanford University Press.

Felman, S. (1987). Jacques Lacan and the adventure of insight psychoanalysis in contemporary culture. Cambridge, MA: Harvard University Press.

Freud, S. (2002). Civilization and its discontents. New York, NY: The Penguin Group. (Originally published 1930)

Freud, S. (2006). Beyond the pleasure principle. In A. Phillips (Ed.), The Freud Reader (pp. 132-195). New York, NY: the Penguin Group. (Originally published 1920)

Heller-Roazen, D. (2005). Echolalias: On the forgetting of language. New York, NY: Zone Books.

Hijuelos, O. (2011). Thoughts without cigarettes: A memoir. New York, NY: Gotham Books.

Klein, M. (1975). The origins of transference. Envy and gratitude and other works 1946-1963. New York: Free Press.

Klein, M., \& Riviere, J. (1964). Love, hate and reparation. New York, NY: Norton.

Nietzsche, F. (1980). On the advantage and disadvantage of history for life. (P. Preuss, Trans.). Indianapolis, IN Hackett Publication Company.

Pavlenko, A. (2007). Autobiographic narratives as data in applied linguistics. Applied Linguistics, 28, 163-188.

Phillips, A. (1998). The beast in the nursery. New York, NY: Pantheon Books.

Stengel, E. (1939). On learning a new language". International Journal of Psychoanalysis, 20, 471-479.

Winnicott, D.W. (2005). Playing and reality. New York, NY: Routledge. 